UDC: 821.134.2.09

DOI: https:/ / doi.org/10.18485/beoiber.2020.4.1.2

\author{
Joan Manuel Soldevilla Albertí1 \\ Institut Ramon Muntaner de Figueres \\ España
}

\title{
LA MAÑANA DE SAN JUAN; \\ LA PERVIVENCIA DE UN EPISODIO CERVANTINO EN LA NARRATIVA BARCELONESA DE LA SEGUNDA MITAD DEL SIGLO XX
}

\begin{abstract}
Resumen
Don Quijote llega a Barcelona la mañana de San Juan, una fiesta tradicional cristiana que había adaptado antiguas fiestas populares que celebraban el solsticio de verano. Para subrayar que sus personajes iban a vivir los momentos decisivos de sus aventuras, Cervantes quiso que su llegada tuviese lugar en fecha tan simbólica. A mediados del siglo XX, cuatro novelistas fundamentales de la literatura española como han sido Carmen Laforet, Luis Romero, Juan Marsé y Eduardo Mendoza retomaron el motivo forjado por Cervantes y lo incorporaron a algunos de sus títulos decisivos. Este artículo rastrea y analiza la pervivencia de la madrugada de San Juan barcelonesa en Nada, La noria, Últimas tardes con Teresa y La verdad sobre el caso Savolta.

Palabras clave: Don Quijote, Carmen Laforet, Luis Romero, Juan Marsé, Eduardo Mendoza.

\section{SUNRISE ON SAINT JOHN'S DAY. \\ THE SURVIVAL OF A CERVANTINE EPISODE IN THE BARCELONESE NARRATIVE OF THE SECOND HALF OF THE 20TH CENTURY}

\section{Summary}

Don Quixote arrives in Barcelona at sunrise on Saint John's day, a traditional Christian festivity that had adapted some ancient popular festivals which celebrated the summer solstice. That context was a clear foreboding that Cervantes' characters were to live the turning points of their adventures: Cervantes intended them to arrive to Barcelona on such a symbolic date. In mid-twentieth century, four great Spanish novelists, namely Carmen Laforet, Luis Romero, Juan Marsé and Eduardo Mendoza, retrieved the motif which had been created by Cervantes and used it in some of their major works. This article tracks and

1 jsoldevi@xtec.cat
\end{abstract}


analyses the appearance of such a setting as Barcelona at sunrise on Saint's John day in the books Nada, La Noria, Últimas tardes con Teresa and La verdad sobre el caso Savolta.

Keywords: Don Quixote, Carmen Laforet, Luis Romero, Juan Marsé, Eduardo Mendoza.

\section{Cervantes, don Quijote y la mañana de San Juan.}

Barcelona es la ciudad de don Quijote, la única que visita el ingenioso caballero y el lugar donde empieza a morir. A partir de esta evidencia incuestionable, mucho se ha escrito (Canavaggio 1987; Riquer 1989; Riera 2005: 33-43; Micó 2004; García López 2015; Soldevilla 2016) sobre las posibles estancias de Cervantes en la ciudad, sobre el porqué de la significativa presencia de la capital catalana en la narrativa cervantina a partir de 1610, o alrededor de las motivaciones del autor para llevar a su personaje hasta ella; de las más evidentes y explícitas -a saber, diferenciarse del falso Quijote de Avellaneda que había ido a Zaragoza-, a aquellas que querrían subrayar cómo el encuentro con el mar o con una ciudad comercial eran los mejores escenarios para enmarcar la inexorable derrota de un pequeño hacendado manchego de secano que, enloquecido, vivía anclado en un anacronismo imposible y ridículo.

Sea como fuere, la presencia de Barcelona en la novela es tan rotunda como inolvidable para el lector. Y como las cosas inolvidables son las que dejan huella en la memoria, en este artículo queremos rastrear cómo el episodio de la llegada de Don Quijote a Barcelona un 24 de junio ha perdurado en la literatura española hasta nuestros días. Cuando menos, hasta el siglo XX.

Don Quijote y Sancho llegan a Barcelona la mañana de San Juan (Cervantes 2004: 1234). Acompañados de Roque Guinart y de seis de sus hombres son conducidos hasta las puertas de la ciudad amurallada, cuando aún es de noche. El caballero llega a oscuras, en un momento en que, extrañamente, la urbe parece dormir. Muy extrañamente, pues es la noche de San Juan, la más mágica del año. Quizás ha llegado ya a la hora del retiro tras las verbenas y celebraciones, que podemos suponer que las había en aquellos tiempos. «Y no tardó mucho cuando comenzó a descubrirse por los balcones del oriente la faz de la blanca aurora» (Cervantes 2004: 1234). Es la mañana de San Juan, la misma que fascinó y embrujó al Conde Arnaldos del romance medieval y que tanta presencia tuvo en la literatura tradicional. La ciudad se despereza después de una noche breve y cálida; la aurora es mágica, pues no solo surge alegrando «las yerbas y las flores», sino que lo hace en compañía de «chirimías y atabales, ruidos de cascabeles», «trapa, trapa, aparta, aparta» que se oyen surgir desde dentro de la ciudad. El caballero y el escudero ven salir el sol, y quedan fascinados ante el mar que contemplan por primera vez, y que «parecióles espaciosísimo y largo, harto más que las lagunas de Ruidera», comentario irónico que deja clara la mirada cervantina sobre la realidad y sus personajes. El día estalla, literalmente, 
y las banderas ondean al viento; desde los cañones de las galeras y desde tierra se dispara «infinita artillería» (Cervantes 2004: 1235), la alegría y el goce parecen imponerse. «El mar alegre, la tierra jocunda, el día claro solo tal vez turbio del humo de la artillería» (Cervantes 2004: 1235) acompaña la llegada de nuestros héroes. La jornada es vibrante, la luz se impone, el olor de la pólvora festiva se entremezcla con los ruidos del ir y venir de las gentes, que corren, que salen a celebrar la festividad, que se engalanan para tal ocasión.

La llegada en fecha tan señalada no es baladí; más allá de las hipótesis que formulan una posible estancia de Cervantes en Barcelona en día tan singular y señero, y que luego él quiso evocar en este pasaje (Riera 2005: 33-43), lo que está claro es que esta celebración popular conmemoraba y conmemora la llegada del solsticio de verano siendo de esta manera una fiesta cargada de profundo simbolismo. En ella se celebra el esplendor de la naturaleza y la generosidad de sus frutos, se convierte en un canto al amor y a los nuevos tiempos de la luz donde el imperio del sol será rotundo. Momento, pues, de metamorfosis y transformación, de cambios definitivos e irreversibles como los que va a vivir, a partir de ese momento, don Quijote.

De todos es sabido que el santoral cristiano adaptó las celebraciones paganas al nuevo orden religioso y quiso incorporarlas, transformándolas en efemérides de la nueva religión. Así se hizo con la festividad de San Juan, el día más largo del año, donde quedaron, eso sí, rémoras precristianas tan potentes como son, por ejemplo, las hogueras que en el siglo XXI, aunque reguladas y controladas según corresponde a la sensibilidad de nuestros tiempos, perduran en infinidad de poblaciones españolas.

Joan Amades, el folklorista que en los años cincuenta del pasado siglo recogió en su monumental Costumari català gran parte de las tradiciones populares catalanas, subraya cómo Cervantes no hizo ninguna referencia a esas hogueras en día tan señalado:

És molt remarcable que Cervantes fa arribar don Quixot a Barcelona la vigília de Sant Joan i no explica que s'encenguessin focs. En altres dues obres en què situa els personatges a Barcelona, durant la data d'avui, tampoc no diu res de les fogueres. Aquest detall porta a creure que possiblement a les darreries del segle XVI no es devien encendre fogueres dins el clos de la ciutat, i és probable que si se n'encenien per les pagesies dels voltants, no devien tenir gaire importància quan aquell eminent escriptor, tan bon pintor de costums, no en fa la més mínima referència. 2 (Amades 1983: 33)

2 «Es muy remarcable que Cervantes hace que don Quijote llegue a Barcelona la vigilia de San Juan y no explica que se encendiesen hogueras. En otras dos obras en las que sitúa los personajes en Barcelona en esa fecha, tampoco dice nada de las hogueras. Este detalle lleva a considerar que, posiblemente, a finales del siglo XVI no se debían de encender dentro del recinto de la ciudad, y es probable que si se encendían por los campos cercanos, no debían de tener mucha importancia cuando aquel eminente escritor, tan buen pintor de costumbres, no hace la más mínima referencia.» (Trad.a.) 
Amades sostiene (1983: 33) que, seguramente, el miedo a los incendios propició que esas hogueras, ritual simbólico donde se quema el pasado y se renace a una nueva vida, se encendiesen fuera del núcleo urbano, aunque también subraya cómo la costumbre se fue extendiendo intramuros hasta el punto de que en 1789 tuvieron que ser prohibidas en Barcelona para evitar males mayores.

Don Quijote llega a la ciudad y asiste en primera línea a la sorprendente fiesta que conmemora la jornada; contemplando cómo las galeras, hasta hacía poco amarradas:

Comenzaron a moverse y a hacer un modo de escaramuza por las sosegadas aguas, correspondiéndoles casi al mismo modo infinitos caballeros que de la ciudad sobre hermosos caballos y con vistosas libreas salían. Los soldados de las galeras disparaban infinita artillería, a quien respondían los que estaban en las murallas y fuertes de la ciudad, y la artillería gruesa con espantoso estruendo rompía los vientos, a quien respondían los cañones de crujía de las galeras. (Cervantes 2004: 1235)

La pirotecnia se pone al servicio del festejo como aún hoy ocurre en las fiestas de San Juan que se celebran en tantas poblaciones mediterráneas $\mathrm{y}$, específicamente, en Barcelona. La algarabía, el goce, se expande en todas las gentes, y por eso no es extraño que unos pillastres, unos golfillos callejeros que se divierten en mañana tan ruidosa, al ver entrar a personajes tan pintorescos y cómicos como el caballero y su escudero se diviertan gastándoles una broma.

(...) y los muchachos que son más malos que el malo, dos dellos traviesos y atrevidos se entraron por toda la gente $y$, alzando el uno de la cola del rucio y el otro la de Rocinante, les pusieron y encajaron sendos manojos de aliagas. Sintieron los pobres animales las nuevas espuelas y, apretando las colas, aumentaron su disgusto de manera que, dando mil corcovos, dieron con sus dueños en tierra. Don Quijote, corrido y afrentado, acudió a quitar el plumaje de la cola de su matalote, y Sancho, el de su rucio. (Cervantes 2004: 1236)

Algo de mascarada, de fiesta popular tiene esta recepción, pues en medio de las explosiones y atabales, la caída de don Quijote y Sancho parece una celebración más. Sí que surge la intención de castigar a esos gamberros, pero consiguen escapar porque «se encerraron entre más de otros mil que les seguían». Más allá de la hipérbole, es evidente que la jarana es monumental y por eso la fiesta debe continuar, es por ello que «Volvieron a subir don Quijote y Sancho; con el mismo aplauso y música llegaron a la casa de su guía.» (Cervantes 2004: 1237)

En la novela irrumpe el mar, entramos en la ciudad, cambiamos de escenario, de entorno, de realidad; nos acercamos al desenlace de la novela y a la derrota y muerte del caballero: ha llegado el momento de la transformación. Para marcar un momento tan transcendental, don Quijote debe entrar en la ciudad en el momento en que cambia el ciclo natural, cuando definitivamente se entra en un nuevo periodo del año y de la vida. 
La mañana de San Juan y Barcelona se hermanan definitivamente a partir de este momento y Cervantes crea una extraña conjunción entre la urbe y el solsticio de verano que nos anuncia la llegada de un tiempo de cambios inexorables para sus personajes. Una conjunción de una festividad, símbolo del cambio, y de una ciudad que podremos rastrear aún, trescientos cincuenta años después, en una serie de obras significativas del siglo XX3.

\section{La literatura de postguerra. Nada.}

En 1944 Carmen Laforet ganó la primera edición del Premio Nadal con su novela Nada, que vio la luz al año siguiente. Mucho se ha escrito sobre este texto fundamental en la historia de la literatura española del que se ha subrayado, entre otras cosas, su carácter existencialista, la fuerza y originalidad de su voz femenina o su mirada desesperanzada sobre la realidad de una ciudad derrotada. Como de todos es sabido, Nada cuenta las peripecias de una chica, Andrea, que llega a Barcelona al poco de acabar la guerra civil para estudiar la carrera de Filosofía y Letras. Instalada en casa de unos parientes trastornados por la contienda, vivirá un complejo y doloroso proceso de crecimiento donde descubrirá la amistad como un valor esencial de la existencia y cómo el ser humano es capaz de lo más sublime y de lo más abyecto.

Si traemos a colación esta novela es por un par de motivos; el primero puede parecer anecdótico, pero es innegable que plantea curiosas coincidencias: Andrea llega a Barcelona y entra en la ciudad por el mismo lugar que lo hizo don Quijote. El caballero manchego llega a la ciudad amurallada de noche, pero por la descripción de las cercanas galeras amarradas, queda claro que entrará a la ciudad por el Portal del Mar, ubicado, más o menos, en la desembocadura de lo que actualmente es la Via Laietana. Andrea llega de noche a la ciudad un día de septiembre, ya dispuesta a empezar el curso, y lo hace en tren, «y con una sonrisa de asombro miraba la gran estación de Francia»; este enclave ferroviario, situado a pocos metros de donde antaño estuvo la puerta de las murallas, se percibe envuelto por «un aire marino, pesado y fresco y a sabiendas de que a mi espalda (...) estaba el mar». La protagonista toma un taxi, en este caso «uno de esos viejos coches de caballos que han vuelto a surgir después de la guerra» y se dirige a la calle de Aribau, donde viven sus familiares. Las indicaciones son escasas, pero bastante claras: «corrí aquella noche por anchas calles vacías y atravesé el corazón de la ciudad hasta que el coche dio la vuelta a la plaza Universidad (...) y enfilamos la calle de Aribau» (Laforet 2010: 71-72). Es decir, emprende el camino desde la avenida del Marquès de l'Argentera,

3 Para una aproximación minuciosa al capítulo LXI de la segunda parte, resulta imprescindible la consulta de las notas y lecturas del tomo segundo -volumen complementario- de la edición de Francisco Rico -Cervantes 2004 - que manejamos. 
donde está la estación de Francia, y llega hasta la Via Laietana, que remonta hasta la ronda Sant Pere; allí el taxi le conducirá hasta la plaza de la Universitat, encarando acto seguido la calle de Aribau. Estas son las anchas calles vacías que recorre, y aunque es cierto que también podría haber subido por las Ramblas -más alejadas de la estación-, estas, siempre bulliciosas, no se corresponden a lo descrito. Sea como fuere, don Quijote y Andrea entran exactamente por el mismo sitio a la ciudad donde van a aprender lo que es la derrota, la aniquilación física, espiritual y moral. Uno morirá como caballero en sus playas, la otra, renacerá transformada.

El segundo motivo que nos lleva a evocar la novela de Laforet se ciñe más al tema de nuestro artículo. La protagonista vive un año en Barcelona, un curso duro, terrible en muchos casos, pero inolvidable. Tras un crudo invierno y una primavera asfixiante, moralmente devastadora, llega el fin de curso y el anuncio del verano liberador; la ciudad, derrotada, cautiva y desarmada, vive un tiempo de oscuridad, de frío y de miedo, correlato del ánimo de la protagonista, o viceversa. No podemos obviar que Andrea, a pesar de todo, y por extraño que nos parezca, vive una situación de privilegio; se hospeda con su familia, que luchó en el bando de los vencedores -aunque ahora todos sean unos desequilibrados- $\mathrm{y}$, a pesar de su precaria situación económica, está lo suficientemente bien relacionada como para poder emprender estudios en tiempos tan difíciles; por si eso fuera poco, su círculo de amistades, integrado por jóvenes herederos de la alta burguesía catalana, vive inmerso en una cierta opulencia, totalmente alejado del frío y del hambre que ella pasa cotidianamente y de la miseria que envuelve a la mayoría de la población.

La llegada de la noche de San Juan es vivida con intensidad; uno de los muchachos proclama «iLa noche de San Juan es la noche de las brujerías y de los milagros!» (Laforet 2010: 228), y Andrea asiste primero a un intento de declaración amorosa de Pons, el tímido amigo de la universidad que la corteja; poco después, casi se embriaga ante el esplendor de la fiesta observada, desde el sórdido piso en el que vive con sus tíos y abuela, como un imposible estallido de libertad:

Cuando llegué a mi casa el aire crepitaba ya, caliente, con el hechizo que tiene esa noche única en el año. Aquella víspera de San Juan me fue imposible dormir. El cielo estaba completamente despejado y sin embargo sentía electricidad en los cabellos y en la punta de los dedos, como si hubiera tormenta. El pecho se me oprimía por mil ensueños y recuerdos.

Me asomé a la ventana de Angustias, en camisón. Vi el cielo enrojecido en varios puntos por el resplandor de las llamas. La misma calle de Aribau ardió en gritos durante mucho tiempo, pues se encendieron dos o tres hogueras en distintos cruces con otras calles. Un rato después, los muchachos saltaron sobre las brasas, con los ojos inyectados por el calor, las chispas y la magia clara del fuego, para oír el nombre de su amada gritado por las cenizas. Luego el griterío se fue acabando. La gente se dispersaba hacia las verbenas. La calle de Aribau se quedó vibrante, enardecida aún y silenciosa. Se oían cohetes lejanos y el cielo sobre las casas estaba herido por regueros luminosos. Yo recordé 
las canciones campesinas de la noche de San Juan, la noche buena para enamorarse cogiendo el trébol mágico de los campos caldeados. Estaba acodada en la oscuridad del balcón, espabilada por apasionados deseos e imágenes. Me parecía imposible retirarme de allí. (Laforet 2010: 228-229)

La vida parece renacer en un conjuro mágico, mezcla de brujería y milagro, de paganismo y fiesta religiosa, y algo de ello percibe Andrea cuando, tras una nueva discusión familiar y pasada la noche, despierta cargada de ilusiones y vida:

Atravesé Barcelona en un tranvía. Me acuerdo de que hacía una mañana maravillosa. Todos los jardines de la Bonanova estaban cargados de flores y su belleza apretaba mi espíritu demasiado cargado también. También a mí me parecía desbordar -como desbordaban las lilas, las buganvillas, las madreselvas, por encima de las tapias-, tanto era el cariño, el angustioso miedo que sentía por la vida y por los sueños de mi amiga... Quizá durante toda la historia de nuestra amistad no haya vivido momentos tan bellos y tan pueriles como los de aquel inútil paseo entre los jardines, en la radiante mañana de San Juan... (Laforet 2010: 234)

Poco sabe Andrea que este momento de epifanía se va a desmoronar dramáticamente pocos días después, en la verbena de San Pedro, en la fiesta de Pons, cuando este le confiese que se ha prometido con una prima suya, Nuria, alguien de su posición y clase social. En ese momento la protagonista, desolada, tocará fondo para renacer, lentamente poco después, gracias a su progresivo proceso de madurez y crecimiento.

La mañana de San Juan se convierte en el marco simbólico de la transformación, en ese instante de epifanía donde las hogueras y la fiesta, el esplendor de la luz y de la nueva estación que se inaugura se conjuran para iniciar una nueva etapa en el recorrido vital de Andrea. La mañana del 24 de junio supone la entrada en una nueva era dentro del recorrido de los protagonistas. Y esto ocurre tanto a inicios del siglo XVII o tras una guerra civil que ha devastado ciudades e individuos.

\section{La narrativa de los años cincuenta. La noria.}

Desde Argentina, donde se había desplazado por motivos profesionales, Luis Romero escribió su primera novela, La noria, que envió al Premio Nadal. La obra fue reconocida con tan prestigiado galardón y vio la luz en 1952 marcando el desembarco de este autor en el panorama literario español.

En su momento, esta novela supuso una verdadera novedad y de ella se destacó su singular y ágil estructura -en cada secuencia se descubría un protagonista distinto-, y su 
dimensión de obra coral, así como su trascendencia en lo que sería la irrupción de la temática social que caracterizaría la narrativa de esa década. La obra gozó de un notable éxito hasta los años setenta, aunque desde entonces ha vivido un sorprendente e injusto olvido. Una reciente reedición (v. Romero 2016) parece querer cambiar esta dinámica. Leída más allá de su coyuntura de gestación y aparición, la novela sorprende por su tempo narrativo y su estilo, certero y controlado, que sabe encontrar un equilibrio entre el poema y la crónica.

La noria cuenta un día en la vida de Barcelona, desde una madrugada hasta la madrugada de la jornada siguiente. Cada capítulo, como decíamos, tiene un protagonista distinto, que aparece acompañado de comparsas que pueblan su pequeño universo; uno de esos comparsas será quien adquirirá la dimensión de protagonista en el capítulo siguiente, y así sucesivamente hasta completar las veinticuatro horas narradas a lo largo de treinta y siete capítulos.

El día escogido es un lunes inconcreto, de finales de primavera, un día anodino y gris en una ciudad que lo es también; pero un día en el que la cercanía de la festividad de San Juan parece ilusionar a alguno de aquellos anodinos y grises personajes que pueblan la ciudad.

El ferrocarril de Sarriá va casi vacío y se sientan junto a la ventanilla abierta. Da gusto aspirar este aire fresco y húmedo del subterráneo. Berta tiene una voz dulce:

-Papá, he pensado que la víspera de San Juan, que tengo libre, podemos ir al rompeolas a comer la coca, como hicimos hace tres años. ¿Te acuerdas qué bien lo pasamos?

Han parado en Bonanova y ahora arrancan nuevamente; el aire aquí es más puro y trae un perfume de campo o jardín. (Romero 2016: 187)

La acción se sitúa pocos días antes de la verbena y de la festividad, cuando su inminencia propicia que los protagonistas de este capítulo -un anciano abandonado ya hace años por su esposa y la hija de ambos, una abnegada y devota enfermera- preparen la celebración con unas pequeñas dosis de ilusión. Porque a pesar de la visión triste que emana de muchos pasajes del libro, en La noria la esperanza sobrevuela la ciudad, como un extraño compañero de cama de un narrador tan omnisciente como misericordioso. A pesar del miedo y la represión que se extienden por las calles, los personajes muestran una notable dignidad para encarar sus derrotas y para ilusionarse, quizás algo ingenuamente, por su futuro. Por eso, de forma harto reveladora, la novela se abre con una madrugada:

Empieza a amanecer. No se sabe cuándo surgió esta leve claridad sobre las azoteas de la ciudad. Una sonoridad desconocida, nueva, vibra en el aire, y en la atmósfera se está produciendo el diario milagro. El reloj de un convento, madrugador y disciplinado da cinco -quizás seis, que tanto vale- campanadas; campanadas de esas que siempre parecen 
sonar lejanas. Por un instante se diría que se ha paralizado el curso de las cosas. (Romero 2016: 9)

La protagonista efímera de este primer capítulo es Dorita, una joven prostituta que se despide en las Ramblas de su cliente, un generoso deportista vasco. Empieza la novela con un día cargado de esperanzas, a pesar de la sordidez de la situación. A partir de ese momento se suceden los capítulos, los personajes y las horas: taxistas, secretarias, estraperlistas, estudiantes, jóvenes casaderas, obreros, empresarios, delincuentes o ancianas irán pasándose el testigo y convirtiéndose en protagonistas de breves capítulos que, juntados unos con otros, nos ofrecerán un intenso retrato de la vida.

Pasa el día y pasa la noche hasta que llegamos hasta una madrugada casi mágica que cerrará la novela. En ese capítulo final -de título inequívoco, El alba-, el protagonista es un sacerdote, mosén Bruguera, un hombre bueno en el buen sentido de la palabra, misericordioso, que piensa en todos aquellos, feligreses o no, a los que puede ayudar con sus pequeñas acciones cotidianas.

En la ciudad se ha abierto un paréntesis y otra vez las gentes se preparan para lanzarse a la vida. Los más todavía duermen, pero el sol aparecerá dentro de un momento y se abrirán los balcones y volverá la vida a los corazones que reposan. Los carros y los camiones van y vienen ya por las calles, y en algunas cocinas se están calentando los desayunos. El mar se empieza a teñir de rojo, y en la montaña, al otro lado, cantan los pájaros la gloria del Creador. Un pitido lejano anuncia que un tren sale de la estación, o que entra en ella. Las gentes tejerán otra vez sus vidas, sus trabajos, sus deseos, sus odios, sus problemas, sus vidas, sus esperanzas, sus anhelos, sus fatigas, sus mentiras, sus sueños, sus esfuerzos, sus generosidades, sus impulsos, sus ternuras; esta historia se repite variantes hace siglos.

Los domingos se leen desde el presbiterio los sucesos parroquiales: bautizos, matrimonios, defunciones; defunciones, bautizos, matrimonios... En las vidrieras se refleja el primer rayo que se rompe en arco iris por el aire de la iglesia. Acaba de salir el sol. (Romero 2016: 280)

Una mañana del mes de junio, a muy pocos días del día de San Juan, la aurora llega a la ciudad y todo el mundo sale a recibirla. Ocurre alrededor de 1950, y el amanecer es una celebración de la vida y de la esperanza; siglos después de que un hidalgo enloquecido y un sencillo aldeano descubrieran maravillados un nuevo mundo en el que el mar brillaba y las murallas de la ciudad estallaban de alegría, los barceloneses que aún llevan en su ropa y su piel la miseria y el miedo despiertan con la ilusión de vivir y forjar un mundo nuevo. 


\section{La narrativa de los años sesenta. Últimas tardes con Teresa.}

En 1965 Juan Marsé recibió por Últimas tardes con Teresa el premio Biblioteca Breve que convocaba la editorial Seix Barral. Fue tras haberlo recibido el año anterior Guillermo Cabrera Infante -por Tres tristes tigres, titulada inicialmente Vista de amanecer en el Trópicoy en 1962 Mario Vargas Llosa por una novela esencial como fue La ciudad y los perros; este reconocimiento a la que era la tercera novela de Marsé supuso el arranque definitivo de la carrera literaria de uno de los novelistas esenciales de la segunda mitad del siglo XX.

La historia del Pijoaparte retrató con lucidez, distancia y una buena dosis de crueldad la vida en una Barcelona escindida donde el mundo burgués, el marginal y el de la lucha antifranquista convivían en un extraño y singular territorio en el que la ambigüedad, el miedo, la máscara y los malentendidos parecían definir las relaciones entre los individuos. Marsé retrató ese mundo con pulso firme, con un estilo que rehuía el objetivismo de la narrativa precedente y abogando por una búsqueda expresiva de notable riesgo donde el narrador, irónico y cruel, exprimía el lenguaje para ahondar en las contradicciones de los individuos y de la sociedad que les rodeaba.

La novela relata la carrera del Pijoaparte, un delincuente de baja estofa del barrio del Carmelo que logra seducir a Teresa, una hija de la burguesía barcelonesa comprometida políticamente, la cual cree que el muchacho es un valiente líder obrero que lucha contra la dictadura. La novela arranca la noche de San Juan:

Hay apodos que ilustran no solamente una manera de vivir, sino también la naturaleza social del mundo en que uno vive.

La noche del 23 de junio de 1956, verbena de San Juan, el llamado Pijoaparte surgió de las sombras de su barrio vestido con un flamante traje de verano color canela; bajó caminando por la carretera del Carmelo hasta la plaza Sanllehy, saltó sobre la primera motocicleta que vio estacionada y que ofrecía ciertas garantías de impunidad (no para robarla, esta vez, sino simplemente para servirse de ella y abandonarla cuando ya no la necesitara) y se lanzó a toda velocidad por las calles hacia Montjuich. Su intención, esa noche, era ir al Pueblo Español, a cuya verbena acudían extranjeras, pero a mitad de camino cambió repentinamente de idea y se dirigió hacia la barriada de San Gervasio. (Marsé 1991: 13)

El pícaro carmelita llegará hasta los barrios pudientes de la ciudad y decidirá colarse en una verbena privada, en una fiesta de los jóvenes herederos de las clases altas barcelonesas donde consigue introducirse gracias a su desparpajo y carácter. A pesar de su osadía, su ingenuidad es manifiesta pues seduce a Maruja, a quien él cree una invitada cuando en realidad es una criada, eso sí, amiga y confidente de Teresa, la bella chica rubia de la que finalmente quedará prendado el Pijoaparte. 
La primera secuencia de la novela describe esa fiesta veraniega, los escarceos del protagonista intentando hacerse pasar por quien no es, las sospechas de los asistentes, los juegos de seducción que culminan con una escena erótica y con la llegada inexorable de la mañana de San Juan:

Bailaron y se besaron en lo más húmedo y sombrío del jardín, inquietando a los pájaros, bajo un cielo rojizo que parecía palpitar entre las ramas de las acacias. El joven del Sur dejó de fingir, de repente, las palabras de amor brotaban ardientes de sus labios, traspasadas, devoradas por la fiebre de la sinceridad: aún en las circunstancias en que por su temperamento intrigante se colocaba en el más alto grado de imprudencia, y por muy lejos que le llevaran su capacidad de mentira y su listeza, algo había en él que le confería cierta curiosa concepción de sí mismo, su propio rango y su estatura espiritual, algo que le obligaba, en determinados momentos, a jugar limpio. (...) Allí, bajo las acacias suavemente teñidas de rosa, con la brisa de la madrugada despertando nuevas fragancias en el jardín, el joven del Sur abrazó y besó a la muchacha por última vez, furiosamente, como si se fuera a la guerra. (Marsé 1991: 23)

En esa primera aparición del protagonista, que se nos va a revelar un hábil mentiroso a lo largo de toda la novela, el joven «dejó de fingir», percibe en ese momento una extraña conjunción cósmica que le hace sentirse devorado por la «fiebre de la sinceridad», algo difícil de explicar y que le lleva a «jugar limpio». Manolo, el Pijoaparte, siente la «brisa de la madrugada» del día de San Juan, y en ese momento, de forma intuitiva, sabe que empieza una nueva etapa en su biografía, un nuevo episodio de su vida que él percibe «como si se fuera a la guerra». Aún no puede saber que esa intuición será precisa y certera.

La mañana de San Juan es un momento mágico donde se revelan verdades escondidas, donde se intuyen realidades desconocidas, donde un golfo de arrabal se siente despojado de sus máscaras y, poseído por un extraño afán de sinceridad, descubre que algo va a cambiar en su existencia. Esa pequeña travesura de colarse en una fiesta, mucho menos peligrosa que las actividades delictivas que ya está llevando a cabo el Pijoaparte en una ciudad que empieza a salir lentamente del letargo de la posguerra, va a convertirse en la entrada a una nueva vida: establecerá contacto con los poderosos, intentará, como un Rastignac o un Bel Ami de pacotilla, ascender socialmente con unas expectativas tan ingenuas como simplonas, determinará, al modo de Lazarillo, «arrimarse a los buenos por ser uno de ellos», descubrirá el amor, como es propio en una noche mágica como la de San Juan y, finalmente, él mismo se convertirá en una fantasía quijotesca inventada por los que le rodean, que creen que es quien no es. En definitiva, esa madrugada del día 24 de junio, día de San Juan, marca el inicio del fin del Pijoaparte. 


\section{La narrativa de la Transición. La verdad sobre el caso Savolta.}

En 1975, coincidiendo con la festividad del Día del Libro, se publicó La verdad sobre el caso Savolta, una novela que marcó un hito en la narrativa del siglo pasado y dio inicio a una nueva etapa en la historia de la novela española. Considerada la primera novela de la Transición, esta obra de Eduardo Mendoza supo aunar la herencia de los autores españoles que en los años sesenta buscaban un nuevo lenguaje narrativo, la propia tradición de la novela hispánica y la influencia de los autores del boom de la literatura hispanoamericana. Todo ello filtrado con el talento personal de Mendoza y su voluntad de reivindicar la recuperación de la fábula como elemento necesario en la novela.

La verdad sobre el caso Savolta es una novela que se desarrolla en Barcelona durante los agitados años de la Primera Guerra Mundial. Gánsteres, espías, pistoleros, terroristas, empresarios, visionarios, gitanillas y periodistas se entremezclan en un relato multiforme y calidoscópico caracterizado por una estructura fragmentaria donde se combinan pasajes narrativos con documentos que quieren tener apariencia de reales. Mendoza, un novelista cervantino de pura cepa, parodiando modelos narrativos como la novela rosa, la de aventuras y la policíaca, construyó una compleja narración que lo consagró, con esta primera novela, como una figura emergente de las letras españolas. Su sólida trayectoria posterior confirmó este inicial juicio.

El protagonismo de la obra recae en el personaje de Javier Miranda, un bienintencionado pasante en un despacho de abogados que se ve inmerso en una compleja conjura política y criminal. Este hitchcockiano héroe por accidente se verá convertido en eventual hombre de confianza de un peligroso arribista, el empresario Lepprince. Más allá de la trama política y social que se nos describe, en este artículo queremos subrayar el hilo argumental melodramático que articula uno de los ejes de la novela. En él, Lepprince abusará de la ingenuidad de Miranda y le animará a que se case con María Coral, la bella gitana de la cual el joven oficinista está enamorado, sin saber que, en realidad, todo es un subterfugio, una tapadera, para enmascarar la relación entre el empresario y la muchacha. Esta situación, que nos evoca indefectiblemente la condición de cornudo consentido de Lázaro de Tormes, será revelada al héroe por su propia esposa en la noche mágica por excelencia: «Una noche de junio, verbena de San Juan, los acontecimientos se precipitaron». (Mendoza 2015: 395)

En esa noche de verdades y revelaciones, María le desvela su humillante condición, lo que provoca que Miranda se vaya de casa y se lance, desolado, a vagar por las calles de una ciudad que vive una fiesta desenfrenada:

Me levanté sin decir palabra y salí de la estancia. Tomé la puerta y me largué a la calle. Frente a la casa, en mitad de la calzada, ardía una pira verbenera. Se oían explosiones y relampagueaban en el cielo los cohetes; sonaban charangas, circulaban en todas 
direcciones gentes vestidas de gala, cubiertos algunos con antifaces y máscaras. Sumido aún en una sustancial estupefacción, recorrí la ciudad entre el bullicio general y di con mis pasos en las Ramblas, que parecían una sala de baile, un circo y un manicomio. (Mendoza 2015: 398)

Coincidirá con un viejo amigo, Perico Serramadriles, quien le acabará de desvelar la realidad que desconocía: todo su círculo de amistades sabía de esta situación que pensaban que él consentía. La revelación llevará a Miranda a querer olvidar, momentáneamente, la verdad, y pasará una noche también desenfrenada en una verbena organizada en la azotea de un edificio por un grupo de desconocidos. La fiesta, grotesca y esperpéntica, le llevará, con más pena que gloria, hasta el alba, hasta la mañana de San Juan:

Recuerdo que me bebí los fondos de todas las botellas y que derroché verborrea, con lo cual me quedé tranquilo.

Clareaba cuando llegué a casa. (Mendoza 2015: 404)

En esa madrugada y tras franquear su puerta se encontrará con un panorama terrible: el intento de suicidio de María, que abriendo la espita del gas habrá intentado quitarse la vida. Miranda la llevará hasta el hospital - «Las calles estaban desiertas. En la encrucijada humeaban las brasas de la fogata extinta» (Mendoza 2015: 405)- donde, finalmente, podrá ser atendida con cierta discreción y se recuperará. Días después, en un diálogo de raíz folletinesca, María le confesará su amor al tiempo que los dos enamorados formularán su proyecto de marcharse y empezar una nueva vida en América. Una fantasía que, finalmente y tras bizantinos avatares, se hará realidad.

En la mañana de San Juan nacen una nueva María Coral y un nuevo Javier Miranda. Su amor, que solo era una mascarada, una pantomima, se transforma en verdad y brota poderoso de entre las cenizas de las hogueras y del suicidio. En esa madrugada singular, el protagonista, extraviado y desconcertado, ingenuo e idealista, salva a su amada para después descubrir que esta le quiere: el melodrama está servido. En esa noche mágica, una vez más, surgen las verdades, por dolorosas que sean, y en esa madrugada la vida renace como nunca.

\section{Conclusiones}

Cervantes recoge un motivo literario tradicional de una fuerza y contundencia extraordinarias y lo sitúa en la Ciudad Condal. El amanecer en Barcelona de la mañana de San Juan se nos desvela como un momento único, una epifanía donde la fiesta y el 
descubrimiento de nuevas realidades se convierten en el pórtico de entrada a una transformación. Don Quijote llega a la ciudad la mañana de San Juan, y a partir de ese momento el mundo cambiará definitivamente para el ingenioso caballero.

Pasan los siglos y la celebración sigue viva, evoluciona, como corresponde a la transformación de la ciudad, que derriba sus murallas y se expande hasta convertirse en una de las capitales fundamentales del Mediterráneo. Pasan las guerras, las hambrunas y las epidemias que castigan Barcelona con crueldad, pero la mañana que celebra el solsticio de verano se mantiene como un canto a la llegada de una nueva etapa. En la cruda posguerra, Andrea percibe esa mañana como uno de esos escasos momentos de plenitud que tiene la oportunidad de vivir en la carcomida ciudad. Unos anónimos personajes de la Barcelona de los años cincuenta observan el amanecer de un día de junio con la esperanza de empezar una nueva vida, siempre igual, pero siempre distinta a la ya vivida. Unos años después, el Pijoaparte descubre que hay vida más allá de la mentira y del engaño, que existe la sinceridad, y que esa verdad solo puede ser revelada en la madrugada de San Juan. En un texto escrito a las puertas de la Transición, un joven desconcertado como Javier Miranda descubre la verdad $y$, tras una noche de renacimiento, salva a su amada y descubre el verdadero amor en esa mañana mágica.

En cuatro décadas distintas, cuatro de los más importantes novelistas catalanes de la literatura española del siglo XX como han sido Carmen Laforet, Luis Romero, Juan Marsé y Eduardo Mendoza, decidieron que en sus primeras novelas -o cuando menos, en sus primeras novelas significativas y transcendentes- apareciese la mañana de San Juan en Barcelona como un momento decisivo para la evolución de sus personajes, de igual manera como lo había hecho Cervantes para enmarcar la llegada de don Quijote a la ciudad donde iba a sufrir su derrota definitiva.

Más allá de influencias directas o inconscientes, de homenajes o casualidades, el motivo tradicional que aparece en el Quijote y es situado por Cervantes en la capital catalana perdura a lo largo de los siglos con idéntica carga de simbolismo, con la misma intensidad expresiva; la vigencia de un autor no solo se mesura por su perdurar a través de los siglos sino también por su capacidad de incidir en los autores posteriores. Escritores barceloneses del siglo XX retomaron en sus ficciones el motivo de la madrugada de San Juan con análogo espíritu al de Cervantes y demostraron, una vez más, la vigencia prodigiosa del autor del Quijote.

\section{BIBLIOGRAFÍA}

Amades, Joan. Costumari català. Barcelona: Salvat Editores/Edicions 62, 1983. Imprès. Belmonte Serrano, José, y José Manuel López de Abiada (eds). Nuevas tardes con Marsé. Estudios sobre la obra literaria de Juan Marsé. Murcia: Nausicaä, 2002. Impreso. 
Caballé, Anna, e Israel Rolón. Carmen Laforet, Una mujer en fuga. Barcelona: RBA, 2010. Impreso.

Canavaggio, Jean. Cervantes. Madrid: Espasa-Calpe. 1987. Impreso.

Cervantes, Miguel de. Don Quijote de la Mancha. Francisco Rico (ed.). Vol. 2. Barcelona: Círculo de lectores/Galaxia Gutenberg, 2004. Impreso.

García López, Jorge. Cervantes: la figura en el tapiz. Barcelona: Pasado y presente, 2015. Impreso.

Giménez Micó, María Jose. Eduardo Mendoza y las novelas españolas de la transición. Madrid: Pliegos, 2000. Impreso.

Gracia, Jordi, y Domingo Ródenas. Historia de la literatura española. Vol. 7. Derrota y restitución de la modernidad, 1939-2010. Madrid: Crítica, 2011. Impreso.

Laforet, Carmen. Nada. Domingo Ródenas de Moya (ed). Madrid: Editorial Crítica, 2001. Impreso.

-. Nada. Rosa Navarro Durán (introd). Jorge García López (rev). Barcelona: Destino, 2010. Impreso.

Marsé, Juan. Últimas tardes con Teresa. Barcelona: Seix Barral, 1991. Impreso.

-. Cuentos completos. Enrique Turpin (ed). Madrid: Espasa, 2003. Impreso.

-. Ronda del Guinardó. Fernando Valls (ed). Madrid: Crítica, 2005. Impreso.

-. Si te dicen que caí. Ana Rodríguez Fischer, Marcelino Jiménez (ed). Madrid: Cátedra, 2010. Impreso.

Martínez Cachero, José María. La novela española entre 1936 y 1980. Historia de una aventura. Madrid: Editorial Castalia, 1985. Impreso.

Mendoza, Eduardo. La verdad sobre el caso Savolta. Ana Rodríguez Fischer (ed). Barcelona: Planeta, 2015. Impreso.

Micó, José María. Don Quijote en Barcelona. Barcelona: Península, 2004. Impreso.

Moix, Llàtzer. Mundo Mendoza. Barcelona: Seix Barral, 2006. Impreso.

Riera, Carme. «Cervantes, el Quijote y Barcelona (Hipótesis de una estancia barcelonesa de Cervantes en 1571)». Anales Cervantinos XXXVII (2005): 33-43. Impreso.

Riera, Carme (ed). El Quijote y Barcelona. Barcelona: Lunwerg, 2005. Impreso.

Riquer, Martín de. Cervantes en Barcelona. Barcelona: Sirmio, 1989. Impreso.

Roger, Isabel M. «Don Quijote y Roque Guinart frente al estilo de vida de los poderosos». Anales Cervantinos XLVIII (2016): 183-201. Impreso.

Rodríguez Fischer, Ana (ed). Ronda Marsé. Barcelona: Editorial Candaya, 2008. Impreso.

Romero, Luis. La noria. Barcelona: Comanegra, 2016. Impreso.

Sanz Villanueva, Santos. Historia de la novela social española (1942-1975). Madrid: Alhambra, 1980. Impreso.

-. La novela española durante el franquismo. Madrid: Gredos, 2010. Impreso. 
-. «Luis Romero y el testimonio crítico». Los otros. Luis Romero. Barcelona: Calambur, 2016. 9-31. Impreso.

Sobejano, Gonzalo. La novela española de nuestro tiempo: En busca del pueblo perdido. Madrid: Mare Nostrum, 2005. Impreso.

Soldevilla, Joan Manuel. Don Quijote en Barcelona. La ciudad imaginada. Figueres: Cal lígraf, 2016. Impreso. 